[Agr. Biol. Chem., Vol. 30, No. 1, p. 42 48, 1966]

\title{
Kinetic Studies on Microbial Activities in Concentrated Solutions.
}

\section{Part. I. Effect of Excess Sugars on Oxygen Uptake Rate of a Cell Free Respiratory System*}

\author{
By Toshimasa Yano, Tadaatsu Nakahara, Shigeo KamiYama and Koichi Yamada \\ Department of Agricultural Chemistry, Faculty of Agriculture, \\ The University of Tokyo, Tokyo \\ Received July 23, 1965
}

\begin{abstract}
Decreases of respiration rates in the presence of excess sugars, substrates and nonsubstrates, were investigated kinetically on the cell free preparation of a Pseudomonas. The schemes of enzyme inhibition which include successive inactive complexes of one mole of enzyme and two and three moles of substrate or one mole of enzyme and one and two moles of inhibitor were shown to fit the experimental results. Water concentrations were not enough to explain the different inhibitory properties of sugars.
\end{abstract}

It is well known that a metabolic activity of a microorganism decreases in the presence of excess solutes. The cause of which is commonly attributed to osmotic pressure of a solution though the mechanism of it does not seem always clear.

Happening to find out that the cell free preparation of a Pseudomonas still shows oxygen uptake and the activity is decreased by excess solutes, authors have attempted kinetic analyses for the phenomena.

\section{MATERIALS AND METHODS}

Preparation of cell free enzyme solution Pseud. ovalis $40 \mathrm{~F}$, a gluconic acid producing bacterium, was shaken at $30^{\circ} \mathrm{C}$ for twenty-four hours in the medium of Table I, and harvested by centrifugation at $6000 \mathrm{~g}$ for five minutes after removal of calcium carbonate. The cells, washed twice with distilled water and suspended in a small amount of $\mathrm{M} / 15$ phosphate buffer solution of $\mathrm{pH} 6.8$, were subjected to ultrasonic oscilation of $10 \mathrm{Kc}$ for ten minutes. The supernatant of the sonicate, centrifuged at $13000 \mathrm{~g}$ for twenty minutes to

* A part of this work was presented at the annual meet. ing of the Agricultural Chemical Society of Japan, Hokkaido, July 1964 .
TABle I. Composition of Culture Medium

\begin{tabular}{|c|c|}
\hline Glucose & 2.0 \\
\hline$\left(\mathrm{NH}_{4}\right)_{2} \mathrm{SO}_{4}$ & 0.4 \\
\hline $\mathrm{KH}_{2} \mathrm{PO}_{4}$ & 0.1 \\
\hline $\mathrm{MgSO}_{4} \cdot 7 \mathrm{H}_{2} \mathrm{O}$ & 0.1 \\
\hline $\mathrm{Fe}\left(\mathrm{NH}_{4}\right)\left(\mathrm{SO}_{4}\right)_{2} \cdot 12 \mathrm{H}_{2} \mathrm{O}$ & 0.002 \\
\hline $\begin{array}{l}\mathrm{MnSO}_{4} \cdot \text { anhyd. } \\
\text { dist. w ater }\end{array}$ & 0.003 \\
\hline $\mathrm{CaCO}_{3} *$ & 1.0 \\
\hline
\end{tabular}

remove debris, was used as the enzyme solution throughout the experiments, being diluted with $\mathbf{M} / 15$ phosphate buffer, if necessary. The activity was checked before every experiment, but significant loss was not found during several days' storage at $0 \sim 2^{\circ} \mathrm{C}$. The oxygen uptake rate of the solution was, without any substrate added, negligible. Oxygen uptake rate was measured manometrically at $30^{\circ} \mathrm{C}$.

Sugars examined Glucose, galactose, and xylose are substrates of respiration; and fructose and sucrose are non-substrates. In experiments on the effects of non-substrates, $1 \%$ glucose was added as the substrate. Preliminary examination showed that the inhibitions by those sugars are reversible. 
KINETICS AND EXPERIMNTAL RESULTS

\section{a) Inhibitions by excess substrates}

Figs. 1 and 2, known as Lineweaver-Burk plots, indicate that the simple Michaelis-

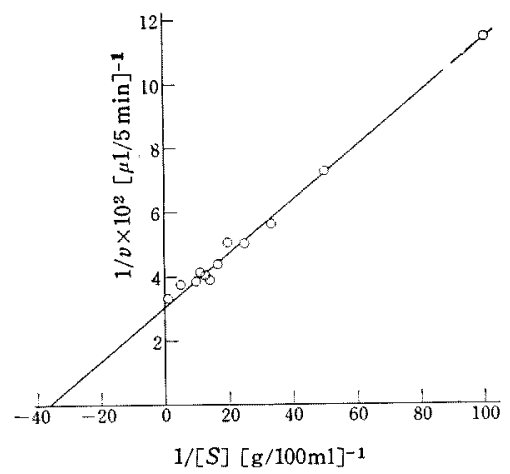

FIG. 1. Determination of $V$ and $K_{1}$ for Glucose.

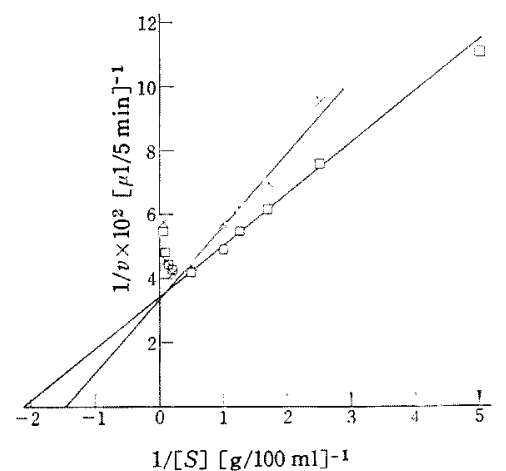

FIG. 2. Determination of $V$ and $K_{1}$ for Galactose and Xylose.

$$
\square-\square \text { Galactose, } \quad x-x \text { Xylose }
$$

Menten equation is applicable for the enzyme system in lower concentrations of the substrates. That is,

$$
\begin{gathered}
E+S \underset{k_{-1}}{\stackrel{k_{1}}{\rightleftarrows}} E S \stackrel{k}{\rightarrow} E+P \\
v=\frac{V}{1+\frac{K_{1}}{[S]}} \text { or } 1 / v=\frac{1}{V}+\frac{K_{1}}{V[S]}
\end{gathered}
$$

The constants, $V$ and $K_{1}$ for each substrate, are obtained from the intercepts of the straight lines on $1 / v$ and $1 /[S]$ axes, respectively. The values are shown in Table II, in which the values of $V$ are expressed as the ratio to the maximum observed respiration rate to eliminate their dependency on enzyme concentration.

Haldane $^{1 /}$ presented a scheme of substrate inhibition, which was generalized by Lineweaver and $\mathrm{Burk}^{2 l}$ as follows:

$$
\begin{gathered}
E+S \underset{k_{-1}}{\stackrel{k_{1}}{\rightleftharpoons}} E S \stackrel{k}{\rightarrow} E+P \\
E S+(n-1) S \stackrel{K_{n}}{\rightleftharpoons} E S_{n} \quad \text { (inactive) } \\
K_{n}=\frac{[E S][S]^{n-1}}{\left[E S_{n}\right]}
\end{gathered}
$$

The rate equation of this scheme is

$$
v=\frac{V}{1+\frac{K_{1}}{[S]}+\frac{[S]^{n-1}}{K_{n}}}
$$

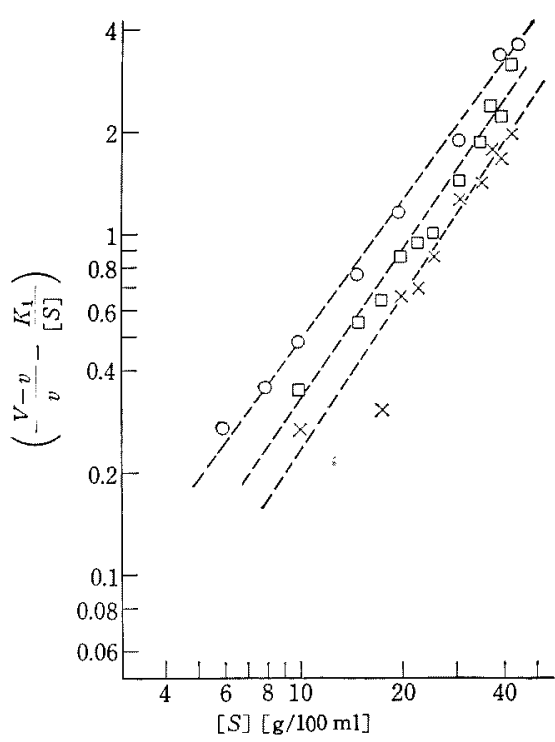

FIG. 3. Examination of Eq. (3).

$\bigcirc \cdots$ Glucose $\square \cdots \square$ Galactose $\times \cdots \times$ Xylose

1) J.B.S. Haldane, "Enzymes", Longmans, London, 1930.

2) H. Lineweaver and D. Burk, J. Am. Chem. Soc., 56, 658 (1934). 
or

$$
\log \left(\frac{V-v}{v}-\frac{K_{1}}{[S]}\right)=(n-1) \log [S]-\log K_{n}
$$

Since the value of $(V-v) / v$ becomes unreliable when $v$ approaches $V$, an adaptability of Eq. (3) is examined in Fig. 3 with the experimental results which were obtained in higher concentrations of the substrates; accepting linearities in the figure, $n=2.3 \sim 2.5$. The odd value of $n$ suggests that more detailed analysis may be possible. Such an example was shown by Weintraub et al. ${ }^{31}$ for the noncompetitive inhibition of $\beta$-amylase by urea. Reanalysis was attempted, taken the value of $n$ into consideration, by the following scheme.

$$
\begin{aligned}
& E+S \underset{k_{-1}}{\stackrel{k_{1}}{\rightleftharpoons}} E S \stackrel{k}{\rightarrow} E+P \\
& E S+S \stackrel{K_{2}}{\rightleftarrows} E S_{2} \quad \text { (inactive) } \\
& E S_{2}+S \stackrel{K_{3}}{\rightleftarrows} E S_{3} \quad \text { (inactive) } \\
& K_{2}=\frac{[E S][S]}{\left[E S_{2}\right]}, \quad K_{3}=\frac{\left[E S_{2}\right][S]}{\left[E S_{3}\right]}
\end{aligned}
$$

The rate equation becomes

$$
v=\frac{V}{1+\frac{K_{1}}{[S]}+\frac{[S]}{K_{2}}+\frac{[S]^{2}}{K_{2} K_{3}}}
$$

or

$$
\left(\frac{V-v}{v}-\frac{K_{1}}{[S]}\right) \frac{1}{[S]}=\frac{1}{K_{2}}+\frac{[S]}{K_{2} K_{3}}
$$

If $[S] \ll K_{2}$ and $K_{3}$, Eq. (4) reduces to Eq. (1). Fig. 4 shows that Eq. (5) is applicable to the experimental results. The constants, $K_{2}$ and $K_{3}$ of each substrate, are obtained from the intercepts of the ordinate and the slopes of the straight lines of Fig. 4. The constant $K_{3}$ will also be obtained from the intercepts of the abscissa. Values of the constants in Eq. (4) are summarized in Table II.

\footnotetext{
3) Weintraub, B. D., G.A. Hamilton, C. Henshaw, and
} A. M. Chase, Arch. Biochem. Bioyhys., 107, 224 (1964).

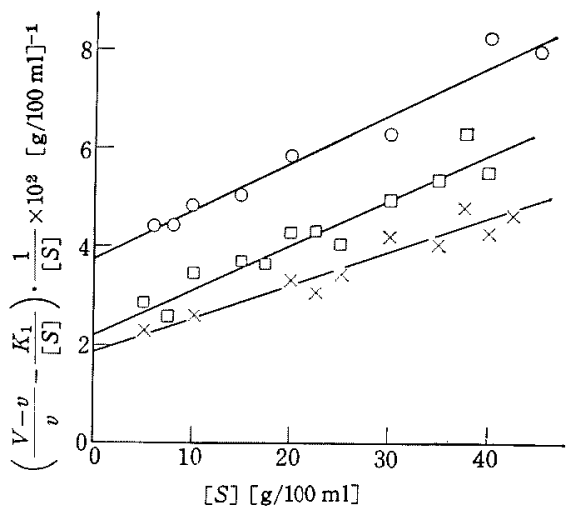

FIG. 4. Determination of $K_{2}$ and $K_{3}$ of Substrates. $O-O$ Glucose $\quad \square-\square$ Galactose $x-x$ Xylose

Table II. Values of the Constants IN EQ. (4) $\begin{array}{lcccc}\text { Substrate } & V / v^{*} & \begin{array}{c}K_{1} \\ {[\mathrm{~g} / 100 \mathrm{ml}]}\end{array} & \begin{array}{c}K_{2} \\ {[\mathrm{~g} / 100 \mathrm{ml}]}\end{array} & \begin{array}{c}K_{3} \\ {[\mathrm{~g} / 100 \mathrm{ml}]}\end{array} \\ \text { Glucose } & 1.04 & 0.028 & 27 & 37 \\ \text { Galactose } & 1.23 & 0.48 & 44 & 26 \\ \text { Xylose } & 1.24 & 0.65 & 55 & 27\end{array}$

By substituting those values of Table II, Eq. (4) was checked again against the observed rates over full concentration range in Fig. 5. Xylose gives a similar result to galactose because the values of corresponding constants of both are similar.

Since the constants, $K_{1}, K_{2}$, and $K_{3}$ are determined, distributions of free enzyme and enzyme-substrate complexes are calculable. Though the present work does not deal with a sole enzyme, morphological distribution of enzyme calculated from the above simplest scheme might be helpful for the reaction to be understood qualitatively. Examples are shown in Figs. 6 and 7.

\section{b) Inhibitions by non-substrate sugars}

Types of inhibition, competitive or noncompetitive, are determined first in Fig. 8, with glucose concentration changed at a fixed concentration $(20 \%)$ of fructose and sucrose.

As the intersection of the straight lines for glucose and fructose falls on $1 /[S]$ axis, the 


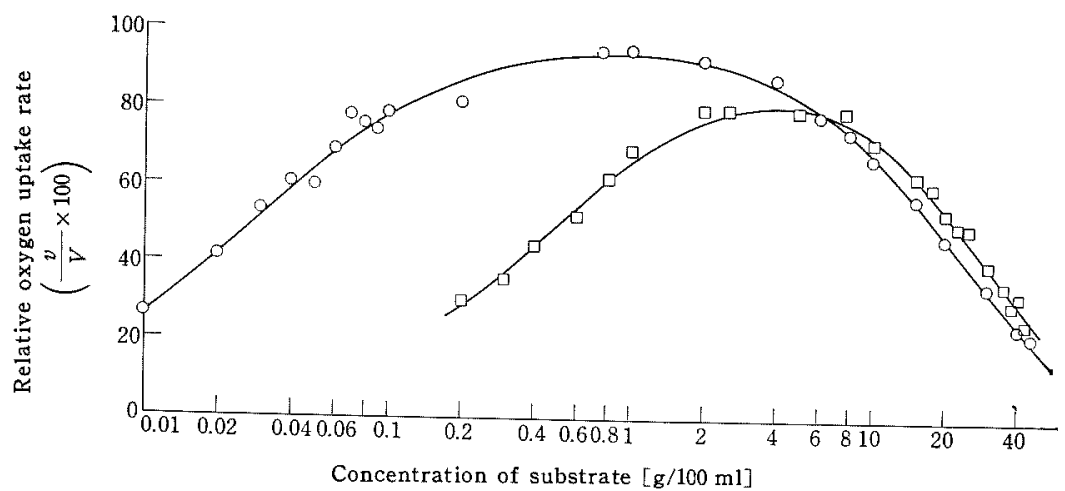

FIG. 5. Comparison of Experimental and Calculated Results.

$O$ : observed rate for glucose

$\square$ : observed rate for galactose calculated rate

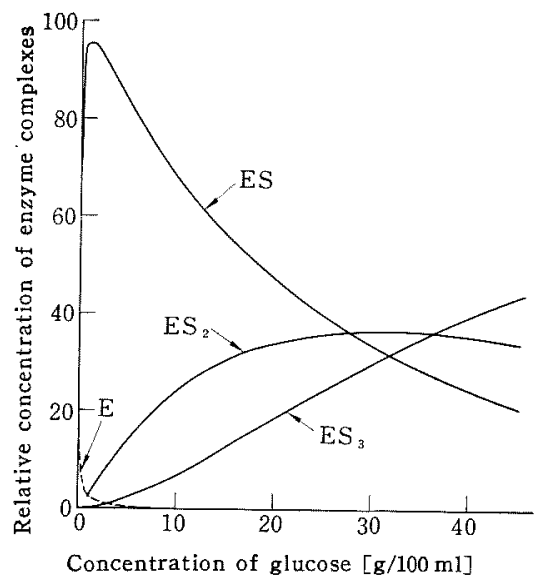

FIG. 6. Morphological Distribution of Enzyme in Glucose Solution.

inhibition by fructose is non-competitive; whereas those of glucose and sucrose fall neither on $1 / v$ and $1 /[S]$ axes, indicating the inhibition by sucrose is intermediate of competitive and non-compectitive.

The slope of the straight line in Fig. 9, $n=1.7$ for fructose, suggests again as has been shown by Weintraub et al. ${ }^{31}$ that the scheme

4) H. A. Lardy, "Respiratory Enzymes", Burgess Publishing Co., Minneapolis, Minn., 1950; W. D. Mc-Elroy and B. Glass, "A Symposium on the Mechanism of Enzyme Action", Mc-Collum-Pratt Institute of the Johns Hopkins Univ., 1954; M. Dixon and E. C. Webb, "Enzymes" London, 1964 etc.

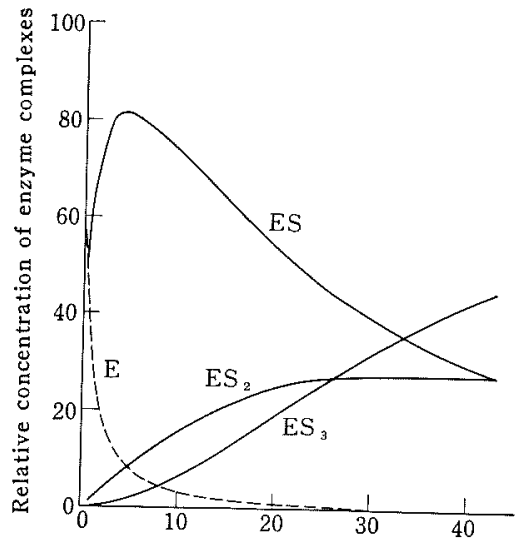

Concentration of galactose $[\mathrm{g} / 100 \mathrm{ml}]$

FIG. 7. Morphological Distribution of Enzyme in Galactose Solution.

of successive inactive complexes of enzyme and inhibitor may be applicable. Such a scheme of inhibition which fits also the results in Fig. 8 will be as follows.

$$
\begin{aligned}
E+S & \stackrel{k_{1}}{\underset{k_{-1}}{\rightleftharpoons}} E S \stackrel{k}{\rightarrow} E+P \\
E+I \stackrel{K_{1}^{\prime}}{\rightleftharpoons} E I & K_{1}^{\prime}=\frac{[E][I]}{[E I]} \\
E S+I \stackrel{K_{1}^{\prime \prime}}{\rightleftarrows} E S I & K_{1}^{\prime \prime}=\frac{[E S][I]}{[E S I]}
\end{aligned}
$$




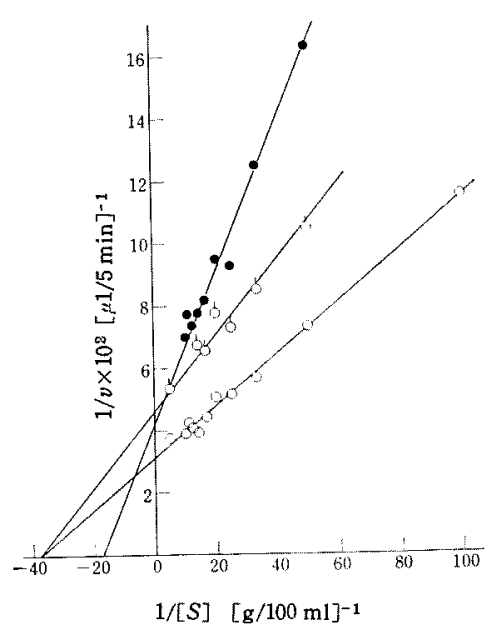

FIG. 8. Determination of Types of Inhibition.
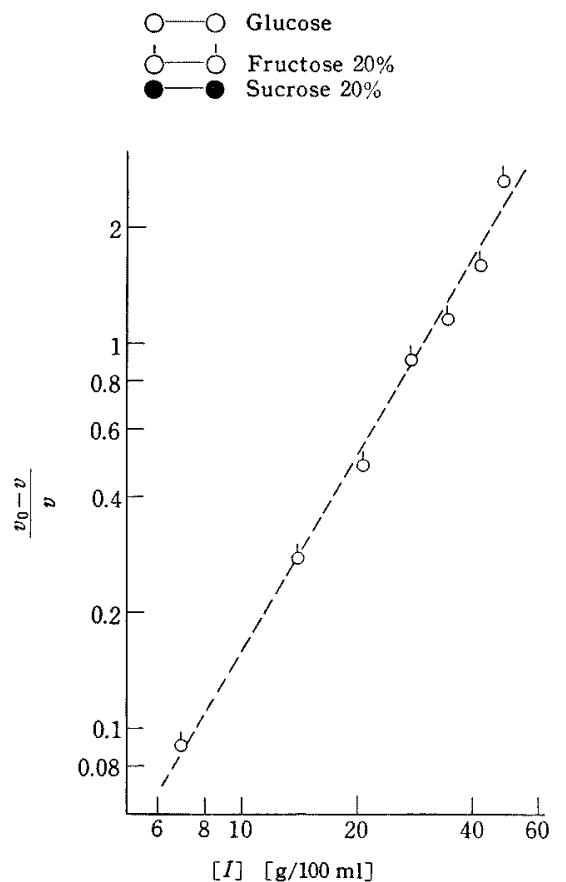

FIG. 9. Plot of $\left(v_{0}-v\right) / v$ vs. [I].

$$
\begin{aligned}
E I+I \stackrel{K_{2}{ }^{\prime}}{\rightleftharpoons} E I_{2} & K_{2}{ }^{\prime}=\frac{[E I][I]}{\left[E I_{2}\right]} \\
E S I+I \stackrel{K_{2}^{\prime \prime}}{\rightleftharpoons} E S I_{2} & K_{2}{ }^{\prime \prime}=\frac{[E S I][I]}{\left[E S I_{2}\right]}
\end{aligned}
$$

The rate equation becomes

$$
v=\frac{V}{1+\frac{[I]}{K_{1}{ }^{\prime \prime}}+\frac{[I]^{2}}{K_{1}{ }^{\prime \prime} K_{2}{ }^{\prime \prime}}+\frac{K_{1}}{[S]}\left(1+\frac{[I]}{K_{1}{ }^{\prime}}+\frac{[I]^{2}}{K_{1}{ }^{\prime} K_{2}{ }^{\prime}}\right)}
$$

If $K_{1}{ }^{\prime}=K_{1}{ }^{\prime \prime}$ and $K_{2}{ }^{\prime}=K_{2}{ }^{\prime \prime}$, the case of noncompetitive inhibition, Eq. (6) becomes

$$
\begin{aligned}
& v=\frac{V}{\left(1+\frac{K_{1}}{[S]}\right)\left(1+\frac{[I]}{K_{1}{ }^{\prime}}+\frac{[I]^{2}}{K_{1}^{\prime} K_{2}{ }^{\prime}}\right)} \\
& =\frac{v_{0}}{1+\frac{[I]}{K_{1}{ }^{\prime}}+\frac{[I]^{2}}{K_{1}^{\prime} K_{2}^{\prime}}}
\end{aligned}
$$

or

$$
\left(\frac{v_{0}-v}{v}\right) \frac{1}{[I]}=\frac{1}{K_{1}{ }^{\prime}}+\frac{[I]}{K_{1}{ }^{\prime} K_{2}{ }^{\prime}}
$$

If one adds $\mathrm{ES}_{2}$ and $\mathrm{ES}_{3}$ into the scheme, the following equation for non-competitive inhibition is obtained.

$$
\begin{aligned}
v & =\frac{V}{\left(1+\frac{K_{1}}{[S]}+\frac{[S]}{K_{2}}+\frac{[S]^{2}}{K_{2} K_{3}}\right)\left(1+\frac{[I]}{K_{1}{ }^{\prime}}+\frac{[I]^{2}}{K_{1} K_{2}^{\prime}}\right)} \\
& =\frac{v_{0}^{\prime}}{1+\frac{[I]}{K_{1}{ }^{\prime}}+\frac{[I]^{2}}{K_{1}{ }^{\prime} K_{2}{ }^{\prime}}}
\end{aligned}
$$

One may also obtain the equation for competitive inhibition putting $K_{1}{ }^{\prime \prime}=\infty$ and $K_{2}{ }^{\prime \prime}=\infty$ in Eq. (6).

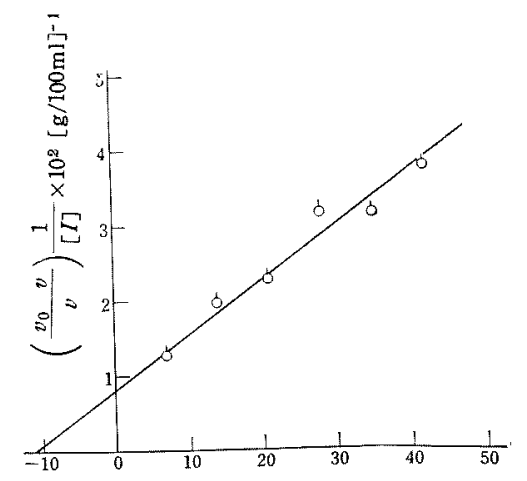

$[I][\mathrm{g} / 100 \mathrm{ml}]$

FIG. 10. Determination of $K_{1}{ }^{\prime}$ and $K_{2}{ }^{\prime}$ of Fructose. 
Eq. (8) is applicable to fructose as shown in Fig. 10, from which $K_{1}{ }^{\prime}$ and $K_{2}{ }^{\prime}$ are estimated as 125 and $11[\mathrm{~g} / 100 \mathrm{ml}]$, respectively.

The morphological distribution of enzyme in fructose solution is shown in Fig. 11. Since the relative concentration of $\mathbf{E S}$ to total enzyme is equal to $v / V$, the comparison of calculated and observed value is also shown in Fig. 11.

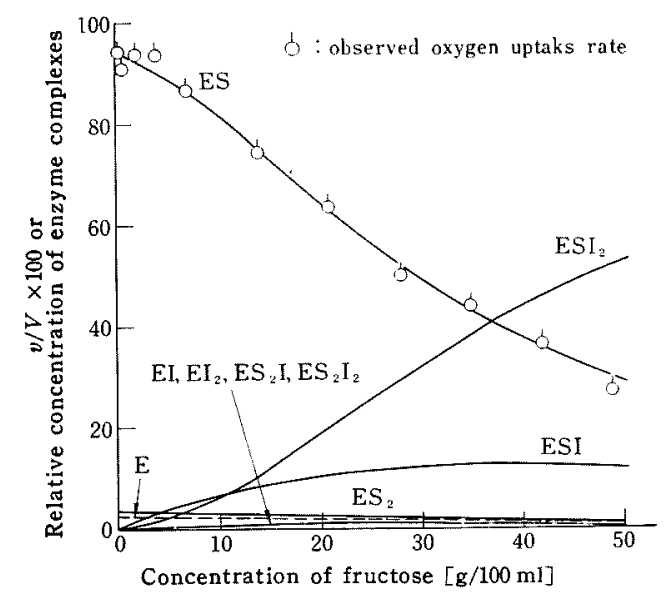

FIG. 11. Morphological Distribution of Enzyme in Fructose Solution Containing 1\% Glucose.

The inhibition by sucrose is intermediate of competitive and non-competitive, and it is difficult to determine the value of each constant in Eq. (6). Eq. (6) is rewritten, however, in the following form which is only useful to show the characteristics of inhibition by sucrose at a fixed substrate concentration.

$$
v=\frac{v_{0}}{1+\frac{[I]}{\alpha}+\frac{[I]^{2}}{\alpha \beta}}
$$

where

$$
\begin{aligned}
& \alpha=\frac{\left(K_{1}+[S]\right) K_{1}^{\prime} K_{1}^{\prime \prime}}{K_{1}^{\prime}[S]+K_{1} K_{1}^{\prime \prime}} \\
& \beta=\frac{\left(K_{1} K_{1}^{\prime \prime}+K_{1}^{\prime}[S]\right) K_{2}^{\prime} K_{2}^{\prime \prime}}{K_{1}^{\prime} K_{2}^{\prime}[S]+K_{1} K_{1}^{\prime \prime} K_{2}^{\prime \prime}}
\end{aligned}
$$

$$
v_{0}=\frac{V}{1+\frac{K_{1}}{[S]}}
$$

Eq. (10) is applicable to fructose as shown in Fig. 12, from which $\alpha$ and $\beta$ are estimated as 47 and $20(\mathrm{~g} / 100 \mathrm{ml}]$ respectively, at the fixed concentration of glucose $1 \%$.

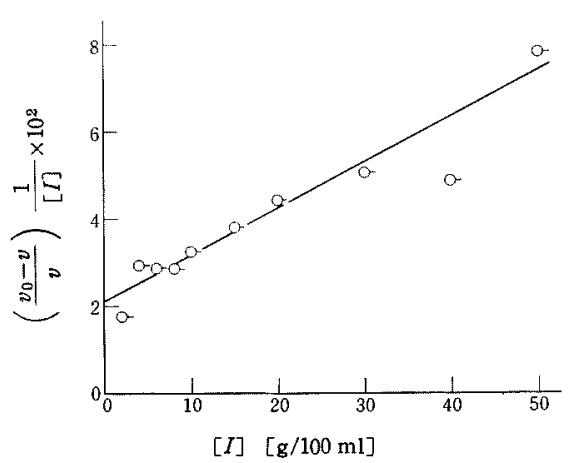

FIG. 12. Estimation of $\alpha$ and $\beta$ of Sucrose in Eq. (10).

\section{DISCUSSION}

Decrease of an enzyme activity in high concentration of solutes was investigated also from the view points of water concentration, ${ }^{5}$ dielectric constant, ${ }^{61}$ and viscosity of solution. ${ }^{71}$

Water concentration of 50\% sucrose solution, for example, is estimated as $730 \mathrm{~g} / 1$ from the specific gravity of the solution, 1.23. If ten moles of water are bound per one mole of sucrose, a little overestimated value from the result of Shiio, ${ }^{9 /}$ the solution still contains $467 \mathrm{~g}$ of free water per liter. Fig. 13, moreover, suggests that water concentration is not the main factor limiting the activity, which agrees with the case of yeast invertase. ${ }^{8}$

The dielectric constants of aqueous solutions of sugars are not very different from that of

5) J. M. Nelson and M.P. Schubert, J. Am. Chem. Soc., 50, 2118 (1928).

6) J.R. Whitaker, A. L. Tappel, and Eva Wormser, Biochim. Biophys. Acta, 62, 300 (1962).

7) A. D. Mc Laren, Enzymologia, 26, 1 (1963).

8) J. Ruchti and A. D. Mc Laren, ibid., 27, 185 (1964).

9) H. Shiio, J. Am. Chem. Soc. 80, 70 (1958). 


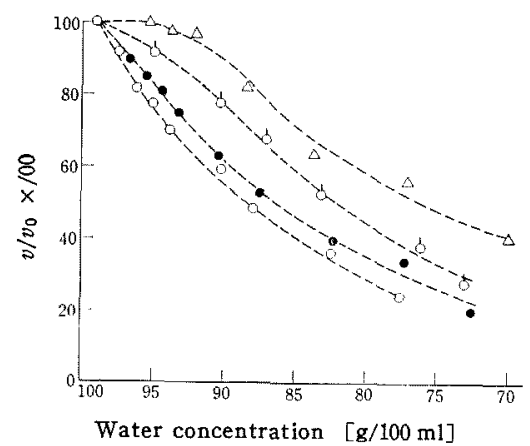

FIG. 13. $v / v_{0}$ vs. Water Concentration.

$v_{0}$ : the oxygen uptake rate in $1 \%$ glucose solution.

$$
\begin{array}{cl}
\Delta \cdots \Delta & \text { Glycerol } \\
\hline \cdots . & \text { Fructose } \\
\cdots \cdots . & \text { Sucrose } \\
\cdots \cdots . & \text { Glucose }
\end{array}
$$

water nor enough to explain the differences in the inhibitory properties of sugars, so is the case of pancreatic $\alpha$-amylase. ${ }^{6 !}$ Viscosity increment or presence of concentrated solutes may decrease the diffusivities of substrate or product. The diffusivity of substrate, however, cannot explain the inhibition by excess substrate. The rate equation presented by Lineweaver and Burk ${ }^{2 \prime}$ for diffusion controlled enzyme reaction does not fit the observed results, too. The diffusivity of product does not seem enough to explain the different properties of inhibition.
Authors are inclined to think the inhibition by excess sugars to the present enzyme system as a chemical reaction.

\section{NOMENCLA TURE}

E: Free enzyme

$S:$ Substrate

$P$ : Product

I: Inhibitor

$E S, E I, E S I$, etc.: Complex of enzyme-substrate, enzyme-inhibitor, enzyme-substrate-inhibitor etc.

$[E],[S],[E S]$, etc.: Concentration of free enzyme, substrate, enzyme-substrate complex, etc.

$k_{1}, k_{-1}, k$ : Reaction rate constant

$K_{1}$ : Michaelis constant or Briggs-Haldane's constant defined as

$$
\frac{k_{-1}+k}{k_{1}}
$$

$K, K^{\prime}, K^{\prime \prime}$ : Dissociation constant of complex of enzyme-substrate, enzyme-inhibitor, and enzyme-substrate-inhibitor, respectively. Suffix shows moles of substrate or inhibitor which combines with one mole of enzyme

$v$ : Oxygen uptake rate

$v_{0}, v_{0}^{\prime}:$ Oxygen uptake rate at $[I]=0$

$v^{*}$ : Observed maximum oxygen uptake rate

$V$ : Theoretical maximum oxygen uptake rate defined as $k\left[E_{0}\right]$, where $\left[E_{0}\right]$ is the concentration of total enzyme

$n$ : Moles of sugar which combines with one mole of enzyme

$\alpha, \beta$ : Empirical coefficient of inhibition 